\title{
Changes of Platelet Phospholipids in Diabetes Mellitus
}

\author{
A. Kalofoutis and $\mathbf{J}$. Lekakis \\ Department of Biological Chemistry, School of Medicine, University of Athens, Greece
}

Summary. In the present study the phospholipid and fatty acid concentration of platelets has been measured in patients with poorly and well controlled diabetes mellitus and in control subjects. An increased phosphatidylethanolamine $(p<0.01)$ and phosphatidylserine $(p<0.001)$ content of platelets was found in poorly controlled diabetes as well as an increased phosphatidylserine $(p<0.001)$ concentration in well controlled diabetes. The most notable changes of platelet fatty acids were a decreased concentration of palmitic $(16: 0 ; p<0.01)$ and linoleic acid $(18: 2$; $p<0.001)$ in the poorly controlled diabetes as well as $(p<0.001)$ and $(p<0.025)$ in the well controlled diabetes, respectively. Also, an increased concentration of arachidonic acid $(20: 4 ; p<0.001)$ was found in both groups of diabetics. No differences were found in phospholipid concentration between patients with and without vascular diseases.

Key words: Diabetes mellitus, metabolic control, platelets, phospholipids, fatty acids.

It is widely recognised that the major problems in diabetes mellitus arise from the insidiously developing vascular complications; in addition to atheromatous changes in the large vessels, diabetics are prone to develop typical lesions involving the small vessels in such diverse tissues as the retina, the renal glomerulus, the muscles and the skin.

It is possible that platelets play an important role in the development of atherosclerotic disease and that platelets adhering to the vessel wall and aggregating with each other represent the initial events in thrombus formation $[1,2]$. Furthermore, it is well documented that in diabetes mellitus platelet function is abnor- mal $[3,4]$ and the activity of platelet factor-3 is increased [5].

Since platelet phospholipids participate in the coagulation process, we set out to investigate the possible changes of platelet phospholipids in patients with diabetes mellitus in the well and poorly controlled state.

\section{Subjects and Methods}

\section{Subjects \\ Sixty-one patients with diabetes mellitus were examined in this study and the results were compared with those obtained from 24 healthy individuals. The patients were divided into the following two groups:}

Group A: Twenty-eight patients with well controlled diabetes mellitus (aged 47-62 years with a mean age of 53 years) who were treated with a diet, oral hypoglycaemic agents or insulin. Eight had no signs of vascular complications, while 20 had one of the following complications: (a) microangiopathy (e.g. retinopathy, nephropathy), (b) large-vesscl disease (e. g. history of myocardial infarction or cerebrovascular accident) or (c) peripheral neuropathy.

The duration of diabetes in these patients was $12 \pm 6$ years and the body weight exceeded the ideal body weight by $10.2 \pm 2.4 \%$ (all expressed as mean $\pm S D$ ). Two patients were suffering from gall bladder disease. Any subject taking drugs other than insulin or oral hypoglycaemic agents were excluded from the study. Criteria for adequate control were: (a) The majority of blood glucose levels should be no more than $7.22 \mathrm{mmol} / 1$ before meals. (b) Urine should be free from ketone bodies and (c) Seventy-five percent of blood glucose levels $2 \mathrm{~h}$ after meals should be no more than $9.99 \mathrm{mmol} / 1$.

Group B: Thirty-three patients with diabetes mellitus in a poorly controlled state who required a change in their previous therapy, if any, were also studied (aged 44-63 years with a mean age of 55 years). Six had no obvious signs of vascular disease, while the remaining 27 had at least one of the vascular complications mentioned above. None of these patients was in diabetic ketoacidosis. The duration of diabetes in this group was $16 \pm 8$ years and the body weight exceeded the ideal body weight by $15.5 \pm 3.2 \%$. Three 
Table 1. Serum lipids and blood glucose concentration in subjects studied

\begin{tabular}{|c|c|c|c|c|c|c|}
\hline & \multirow{2}{*}{$\begin{array}{l}\text { Control subjects } \\
\text { (C) } \\
(n-24)\end{array}$} & \multirow{2}{*}{$\begin{array}{l}\text { Well controlled } \\
\text { diabetics (A) } \\
(n-28)\end{array}$} & \multirow{2}{*}{$\begin{array}{l}\text { Poorly controlled } \\
\text { diabetics (B) } \\
(n-33)\end{array}$} & \multicolumn{3}{|c|}{ Comparison between groups } \\
\hline & & & & $\mathrm{A} / \mathrm{C}$ & $\mathrm{A} / \mathrm{B}$ & $\mathrm{C} / \mathrm{B}$ \\
\hline Age (years) & $49 \pm 6$ & $53 \pm 4$ & $54 \pm 8$ & & & \\
\hline (range) & $42-67$ & $47-62$ & $44-63$ & & & \\
\hline \multicolumn{7}{|l|}{ Duration of } \\
\hline symptoms (years) & & $12 \pm 6$ & $16 \pm 8$ & & & \\
\hline Excess body weight $(\%)$ & $9.5 \pm 2.1$ & $10.2 \pm 2.4$ & $15.5 \pm 3.2$ & & & \\
\hline Glucose $(\mathrm{mmol} / 1)$ & $5.06 \pm 0.33$ & $6.82 \pm 0.60$ & $11.6 \pm 1.1$ & $p<0.001$ & $p<0.001$ & $p<0.001$ \\
\hline Triglyceride (mmol/1) & $1.27 \pm 0.24$ & $1.63 \pm 0.29$ & $1.95 \pm 0.39$ & $p<0.001$ & $p<0.001$ & $p<0.001$ \\
\hline Cholesterol $(\mathrm{mmol} / \mathrm{l})$ & $5.87 \pm 0.85$ & $5.97 \pm 0.8$ & $6.05 \pm 0.95$ & NS & $\mathrm{NS}$ & NS \\
\hline \multicolumn{7}{|l|}{ Phospholipids } \\
\hline$(\mathrm{mmol} / \mathrm{l})$ & $75.9 \pm 8.05$ & $78.5 \pm 10.9$ & $80.17 \pm 11.59$ & NS & NS & NS \\
\hline
\end{tabular}

Results are expressed as mean $\pm \mathrm{SD}$; NS $=$ not significant

patients were suffering from gall bladder disease and two patients from chronic obstructive pulmonary disease.

Group $C$ : This group consisted of the 24 healthy subjects (aged 42-62 years with a mean age of 52 years) with a body weight which exceeded the ideal body weight by $9.5 \pm 2.1 \%$.

\section{Procedures}

Blood samples were drawn early in the morning (between 0700 and $0800 \mathrm{~h}$ ) after an overnight fast, from an antecubital vein and were mixed immediately in siliconised capillary tubes with EDTA $40 \mathrm{mmol} / \mathrm{l}(\mathrm{Ph} 7.24) 4: 1 \mathrm{v} / \mathrm{v}$. Samples were centrifuged at $90 \times \mathrm{g}$ (MSE, Mistral 6L) for $10 \mathrm{~min}$ at $4^{\circ} \mathrm{C}$. The supernatant platelet-rich plasma (two-thirds of the whole plasma volume) was obtained by gentle circular motion with a Pasteur pipette and centrifuged at $4340 \times g$ (Sorvall-RC2B) for $15 \mathrm{~min}$. The pellet was washed twice with $0.15 \mathrm{~mol} / 1 \mathrm{NaCl}$. The platelet pellet was then analysed for total lipids according to the method of Folch et al. [6]. A glass column (length: $20 \mathrm{~cm}$; diameter: $0.5 \mathrm{~cm}$ ) was packed with silicic acid (500 mg, $325 \mathrm{mesh}$, special for lipid chromatography, Bio-rad, Laboratories, Richmond, California) and was used for the separation of total lipids into neutral lipids ( $12 \mathrm{ml}$ chloroform), glycolipids (26 ml of a mixture $1: 2(\mathrm{v} / \mathrm{v})$ of acetone/methanol) and phospholipids (14 $\mathrm{ml}$ of a mixture $1: 2(\mathrm{v} / \mathrm{v})$ of chloroform/methanol).

The phospholipid fraction obtained was evaporated in a nitrogen atmosphere and re-extracted using the same solutions. The phosphorus content of the total phospholipid fractions was estimated by the method of Bartlett [7]. Approximately 150 180 g of phospholipid was used for the separation of various phospholipid classes using two-dimensional thin-layer chromatography (precoated $10 \times 10 \mathrm{~cm}$ silica gel. G plates) based on the method of Kwiterovich et al. [8]. Generally the recovery for this method was $90 \%-94 \%$. The individual phospholipid spots were visualised as follows: the major phospholipid components were identified by spraying the chromatogram with $\mathrm{H}_{2} \mathrm{SO}_{4} / \mathrm{H}_{2} \mathrm{O}(1: 1$, v/v), and heating to $160^{\circ} \mathrm{C}$ for $15 \mathrm{~min}$ and the phospholipid components containing ninhydrin-reacting residues were identified by spraying with a ninhydrin solution $(5.6 \mathrm{mmol} / 1$ ninhydrin-pyridine $3: 1$, $\mathrm{v} / \mathrm{v}$ ) and heating to $80^{\circ} \mathrm{C}$ for $12 \mathrm{~min}$. Each phospholipid class was analysed in duplicate by co-chromatography using commercial phospholipids as standards (Sigma, St Louis). The scraped off spots were digested immediately for phosphorus determinations according to Bartlett's method [7].

The main fatty acids were determined by gas-chromatography in the single platelet phospholipid fraction. The methyl esters of the platelet phospholipid fraction were prepared by conversion of fatty acids to methyl esters employing the method of Dodge and Phillips [9].

The methyl esters were analysed by flame ionisation chromatography (Perkin Elmer 900 gas chromatograph) on a column 3\% ethylene glycol succinate on chromosorb $\mathrm{W}$ at $180^{\circ} \mathrm{C}$. Highly pure nitrogen was used as a carrier gas. Peak identifications were made with reference to methyl esters commercially available and the peak areas were measured by triangulation.

Serum total phospholipid content was determined by using the method of Bartlett [7]. Serum total cholesterol was estimated using the method of Henly as modified by Chiamori and Henry [10] and serum triglycerides by the method of Jovers [11].

All solvents used were redistilled and experiments were made in duplicate. Statistical analysis was carried out by Student's ' $t$ ' test. The results are expressed as the mean of a value \pm standard deviation.

\section{Results}

Table 1 shows the mean values of blood glucose and serum lipids; the increase of triglycerides content in diabetic groups was statistically significant $(p<0.001$ for both groups).

Table 2 shows the variations of platelet total phospholipids as well as the percentage distribution of individual phospholipids in patients and control subjects. Total phospholipids were increased in both the diabetic groups $(p<0.01$ for group A and $p<0.001$ for group B). An increase in phosphatidylserine was found in patients with well controlled diabetes $(p<$ 0.001 ), while in subjects with poorly controlled diabetes fractional increases were found in both phosphatidylserine $(p<0.001)$ and phosphatidylethanolamine $(p<0.01)$. Within the well controlled diabetic group, we observed no significant differences with respect to different treatment modalities. Also, no differences in total and individual platelet phospholipids were observed between patients with and without vascular changes. Moreover a significant increase of 
Table 2. Platelet phospholipid concentrations in diabetic patients and control subjects

\begin{tabular}{|c|c|c|c|c|c|c|}
\hline \multirow{2}{*}{$\begin{array}{l}\text { Phospholipid class } \\
\text { Total phospholipids } \\
\text { (mg/10 cells) }\end{array}$} & \multirow{2}{*}{$\begin{array}{l}\text { Control subjects } \\
\text { (C) }\end{array}$} & \multirow{2}{*}{$\begin{array}{l}\begin{array}{l}\text { Well controlled } \\
\text { diabetics }(\mathrm{A})\end{array} \\
0.52 \pm 0.16\end{array}$} & \multicolumn{2}{|c|}{$\begin{array}{l}\text { Poorly controlled A/C } \\
\text { diabetics (B) }\end{array}$} & \multirow{2}{*}{$\begin{array}{l}\mathrm{A} / \mathrm{B} \\
p<0.05\end{array}$} & \multirow{2}{*}{$\begin{array}{l}\mathrm{C} / \mathrm{B} \\
p<0.001\end{array}$} \\
\hline & & & $0.60 \pm 0.17$ & $p<0.01$ & & \\
\hline Lysophosphatidylcholine & $1.7 \pm 0.4$ & $1.7 \pm 0.3$ & $1.6 \pm 0.4$ & NS & NS & NS \\
\hline Phosphatidylcholine & $38.4 \pm 3.2$ & $37.5 \pm 3.3$ & $37.1 \pm 3.2$ & NS & NS & NS \\
\hline Sphingomyelin & $17.0 \pm 2.1$ & $16.5 \pm 2.5$ & $16.2 \pm 2.4$ & NS & NS & NS \\
\hline Phosphatidylinositol & $9.1 \pm 1.0$ & $9.0 \pm 1.3$ & $8.6 \pm 1.2$ & NS & NS & NS \\
\hline Phosphatidylethanolamine & $27.2 \pm 2.7$ & $28.3 \pm 3.0$ & $29.2 \pm 3.0$ & NS & NS & $p<0.01$ \\
\hline Phosphatidylserine & $5.5 \pm 0.7$ & $6.3 \pm 0.5$ & $6.5 \pm 0.6$ & $p<0.001$ & NS & $p<0.001$ \\
\hline Diphosphatidylglycerol & $0.9 \pm 0.3$ & $0.8 \pm 0.4$ & $0.8 \pm 0.3$ & NS & NS & NS \\
\hline
\end{tabular}

Results expressed as percentage of total phospholipid concentration (mean $\pm \mathrm{SD}$ ). NS $=$ not significant

Table 3. Percentage concentrations of predominant fatty acids in total phospholipid fractions of the diabetic patients and control subjects

\begin{tabular}{lccclll}
\hline Fatty acids $^{a}$ & Control subjects $(\mathrm{C})$ & $\begin{array}{l}\text { Well controlled } \\
\text { diabetics }(\mathrm{A})\end{array}$ & $\begin{array}{l}\text { Poorly controlled } \\
\text { diabetics }(\mathrm{B})\end{array}$ & $\mathrm{A} / \mathrm{C}$ & $\mathrm{A} / \mathrm{B}$ & $\mathrm{C} / \mathrm{B}$ \\
\hline $14: 0$ & $1.0 \pm 0.2$ & $1.1 \pm 0.2$ & $1.2 \pm 0.2$ & $\mathrm{NS}$ & $\mathrm{NS}$ & $\mathrm{NS}$ \\
$16: 0$ & $21.2 \pm 1.2$ & $19.9 \pm 1.0$ & $19.5 \pm 1.1$ & $p<0.001$ & $\mathrm{NS}$ & $p<0.001$ \\
$16: 1$ & $1.2 \pm 0.2$ & $1.3 \pm 0.2$ & $1.2 \pm 0.3$ & $\mathrm{NS}$ & $\mathrm{NS}$ & $\mathrm{NS}$ \\
$18: 0$ & $21.1 \pm 1.3$ & $20.5 \pm 1.4$ & $20.4 \pm 1.3$ & $\mathrm{NS}$ & $\mathrm{NS}$ & $p<0.025$ \\
$18: 1$ & $19.1 \pm 1.0$ & $19.0 \pm 0.9$ & $19.4 \pm 1.1$ & $\mathrm{NS}$ & $\mathrm{NS}$ & $\mathrm{NS}$ \\
$18: 2$ & $7.3 \pm 0.7$ & $6.9 \pm 0.6$ & $6.5 \pm 0.6$ & $p<0.025$ & $\mathrm{NS}$ & $p<0.001$ \\
$20: 4$ & $26.0 \pm 2.0$ & $28.0 \pm 2.1$ & $28.8 \pm 2.3$ & $p<0.001$ & NS & $p<0.001$ \\
Others & $3.0 \pm 0.5$ & $3.3 \pm 0.5$ & $2.9 \pm 0.5$ & NS & NS & NS \\
\hline
\end{tabular}

${ }^{a}$ Fatty acids are designated by number of carbon atoms: number of double bonds. Results expressed as mean \pm SD. NS $=$ not significant

total phospholipids was found in the poorly controlled patients compared with the well controlled group $(p<0.05)$.

Table 3 depicts the concentration of the predominant phospholipids fatty acids of the platelets. The most notable changes in group A (well controlled diabetics) were a decreased concentration of $16: 0(p<$ $0.001)$ and $18: 2(p<0.025)$ as well as an increase in $20: 4(p<0.001)$. In group B (poorly controlled diabetics) a decreased concentration in 16:0 $(p<0.001)$, $18: 0(p<0.025)$ and $18: 2(p<0.001)$ was observed together with an increased concentration in $20: 4(p<$ 0.001) compared with control subjects.

\section{Discussion}

Autopsy and clinical studies have established that atherosclerosis and arterial occlusions are more common in patients with diabetes mellitus than in non-diabetic subjects [12-14]. Abnormal platelet function has been implicated in the pathogenesis of the arterial lesions; these abnormalities include an increased sensitivity to aggregating agents, increased platelet factor- 3 activity and increased adhesiveness [5, 15-17].

The present study shows that patients with diabetes mellitus, in addition to having abnormalities in total plasma lipids, have changes in platelet total phospholipid content as well as in individual phospholipid classes. The increased concentration of platelet total phospholipids observed in this study could account for the increased release of coagulation-active phospholipids (platelet factor-3) that has been described in diabetes [5]. Moreover the increase in platelet phospholipids is higher in the group of the patients with poorly controlled diabetes. This observation may reflect an increased platelet malfunction in these patients compared with those with well controlled diabetes, a fact that could explain the higher risk which poorly controlled diabetics have of developing atherosclerotic lesions. In relation to the individual phospholipid classes, an increase in phosphatidylserine concentration was observed in both diabetic groups as well as an increase in phosphatidylethanolamine in poorly controlled diabetics. It is well known that these two phospholipids have a great significance for the clotting mechanism [18]. Moreover phosphatidylethanolamine is related to the regulation of blood viscosity [19]. The above mentioned observation of the increased platelets phospholipids content is in agreement with the previous findings of Nordoy and Rodset [5] who noticed a moderate absolute increase of total phospholipid in platelets of patients with juvenile diabetes and maturity onset 
diabetes. In their study the absolute amounts of the various phospholipids revealed an increase of phosphatidylserine in both groups and an additional increase in other main phospholipid fractions in the maturity onset groups, but the percentage distribution of the various fractions showed only in significant variations. It must be noted that all these patients were well controlled with approximately normal blood glucose levels at the time of testing.

Another finding of the present study is the independence of platelet phospholipid abnormalities from the existence or non-existence of vascular complications. This observation supports the findings of other investigators who reported that platelet dysfunction is also observed in diabetics without obvious vascular disease $[3,17]$. The changes referred to above could be related partly to the possibly different dietary intake of fatty acids. Of course, ideally the results should be compared with a control group taking a known diabetic diet.

Halushka et al. [20] reported that platelets from patients suffering from diabetes mellitus show an increased synthesis of prostaglandin E-like material following exposure to small doses of ADP, adrenaline or collagen. This finding could be related to the pathogenesis of the abnormal sensitivity of these platelets to aggregating agents. The increased concentration of arachidonic acid (20:4) in platelet phospholipids observed in the present study could contribute to the increased synthesis of prostaglandins in diabetes. However, an increased activity of phospholipase $\mathrm{A}$ in diabetics cannot be excluded and further investigation is required to elucidate this point.

Another important observation of the present study is the reduced concentration of linoleic acid $(18: 2)$ in patient groups. Fleischman et al. [21] have reported that a diet rich in linoleic acid $(18: 2)$ can improve the abnormal platelet aggregation found in diabetics. Thus our finding of a decreased concentration of linoleic acid $(18: 2)$ could be of significance.

There is no doubt that further investigation is required to clarify the exact role of linoleic acid in platelet function and to explore its possible use as a therapeutic agent for the prevention of atherosclerosis in diabetes mellitus.

\section{References}

1. Mustard JF, Packham MA (1969) Factors influencing platelet function: adhesion release and aggregation. Pharmacol Rev 22: 97-187
2. Mustard JF (1972) Platelets and thrombosis in acute myocardial infarction. Hosp Pract 7: 115-128

3. Sagel J, Colwell JA, Crook L, Laimins M (1975) Increased platelet aggregation in early diabetes mellitus. Ann Intern Med 82: 733-738

4. O'Malley BC, Ward JD, Timperley WR, Porter NR, Preston FE (1975) Platelet abnormalities in diabetic peripheral neuropathy. Lancet $21: 1274-1276$

5. Nordoy A, Rodset JM (1970) Platelet phospholipids and their function in patients with juvenile diabetes and maturity onset diabetes. Diabetes 19:698-702

6. Folch J, Lees M, Sloane-Stanley GH (1957) A simple method for the isolation and purification of total lipids from animal tissues. J Biol Chem 226: 497-509

7. Bartlett GR (1959) Phosphorus assay in column chromatography. J Biol Chem 234: 466-468

8. Kwiterovich RO, Sloan MR, Fredrickson DS (1970) Glycolipids and other lipid constituents of normal human liver. J Lipid Res II : $322-330$

9. Dodge JT, Phillips GB (1967) Composition of phospholipids and phospholipid fatty acids and aldehydes in human red cells. J Lipid Res 8: 667-675

10. Henly AA (1963) Determination of total cholesterol and cholesterol esters. In: Henry TR (ed) Clinical chemistry. Harper and Row, New York, p 855

11. Jovers A (1963) Technique for determination of serum glycerides. J Lipid Res 4: 228-231

12. Bell ET (1952) A postmortem study of vascular disease in diabetics. Arch Pathol 53:444-455

13. Feldman M, Feldman MJR (1954) The association of coronary occlusion and infarction with diabetes mellitus. Am J Med Sci 228: $53-56$

14. Pathania NS, Sachar RS (1961) Cardiovascular complications of diabetes mellitus. Br Med J I: 1505-1508

15. Shaw S, Pegrum GD, Wolff S, Ashton WL (1967) Platelet adhesiveness in diabetes mellitus. J Clin Pathol 20:845-847

16. Seth HN (1973) Fibrinolytic response to moderate exercise and platelet adhesiveness in diabetes mellitus. Acta Diabet Lat 10: 306-314

17. Colwell JA, Halushka PV, Sargi K, Levine J, Sagel J, Nair RMG (1976) Altered platelet function in diabetes mellitus. Diabetes 25: 826-831

18. Nordoy A, Rodset JM (1970) Platelet phospholipids and their function in patients with ischemic heart disease. Acta Med Scand 188: 133-137

19. Nemerson Y (1968) The phospholipid requirement of tissue factor in blood coagulation. J Clin Invest 47:72-80

20. Halushka PV, Lurie D, Colwell JA (1977) Increased synthesis of prostaglandin E-like material by platelets from patients with diabetes mellitus. N Engl J Med 297: 1306-1310

21. Fleischman AR, Beirenbaum ML, Stier A, Somol HS, Watson $\mathrm{PB}$. (1976) In vivo platelet function in diabetes mellitus. Thromb Res 9:467-471

Received: 19 March 1980

and in revised form: 11 June 1981

Dr. Anastasios Kalofoutis

Department of Biological Chemistry

School of Medicine, University of Athens

Goudi (609) Athens, Greece 